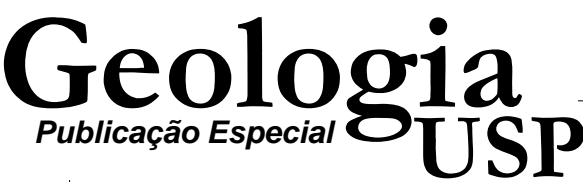

\section{Um Olhar Crítico dos Alunos Sobre o Curso de Bacharelado em Geologia}

\author{
Lucas Padoan de Sá Godinho (lucas@kico.com.br), Marcos Saito de Paula, Paulo Henrique de Oliveira, \\ Nicolás Misailidis Strikis, Flávio Rogério da Silva \\ Graduação em Geologia - Instituto de Geociências - USP \\ R. do Lago 562, CEP 05508-080, São Paulo, SP, BRA
}

Recebido em 12 de dezembro de 2006; aceito em 12 de março de 2007

Palavras-chave: estrutura curricular, Bacharelado em Geologia.

\section{RESUMO}

O objetivo deste trabalho é o de discutir os principais problemas que existem na estrutura curricular do curso de Bacharelado em Geologia do Instituto de Geociências - USP, e em algumas disciplinas, sob o ponto de vista dos alunos. Em discussões entre representante discente e o CEPEGE, e em uma série de reuniões em caráter de assembléia, ocorridas em 2006, problemas foram levantados e discutidos, e propostas para saná-los foram indicadas. Entre os principais tópicos levantados consta o descaso pela graduação, a falta de qualidade das disciplinas oferecidas aos estudantes de Geologia por outros institutos, o melhor aproveitamento dos campos oferecidos nos dois primeiros anos de curso e a concentração das principais disciplinas no terceiro e quarto anos, sobrecarregando o aluno.

Keywords: curricular structure, Geology Bachelorship.

\begin{abstract}
The aim of this paper is to discuss the main problems in the curricular structure of the Bachelors' Geology Course of the Geosciences Institute - USP, and in some subjects, from the students' point of view. In discussions between a student representative and the CEPEGE, and in some assemblies during 2006, some problems were noticed and discussed, and proposals to correct them were considered. Some of the main topics were the indifference shown with the graduation course, the low quality of the subjects offered to the geology students by other institutes, a better use of the field excursions undertaken during the first two years of the course, and the concentration of many important subjects in third and forth years, overloading the course.
\end{abstract}




\section{INTRODUÇÃO}

Os autores deste texto querem ressaltar também que o objetivo das reuniões e discussões visou uma avaliação do Curso de Bacharelado em Geologia no contexto dos próprios alunos, e não uma reestruturação curricular de ordem global. Preocupou-se mais com as disciplinas, conteúdos e forma como são ministradas, pois é do entendimento dos alunos que o momento é muito oportuno. Pela própria natureza dos problemas é mais fácil que estes sejam primeiramente apontados e discutidos pelos alunos, do que problemas de ordem maior, como estrutura curricular em si, dada a própria posição do aluno em relação ao curso, ou seja, uma visão de dentro do curso, facilitando a percepção de problemas mais pontuais.

As disciplinas que não são citadas nesse texto foram consideradas boas ou satisfatórias entre os alunos que participaram das reuniões. As disciplinas que não tiveram opinião e debate o suficiente para avaliá-las, como é o caso das disciplinas do $4^{\circ}$ ano, também não foram incluídas no texto.

No contexto geral, o currículo do curso de bacharelado é bom, de acordo com os alunos, porém, existem alguns problemas, e alguns deles são conhecidos há algum tempo, como a concentração de matérias e aulas de campo no sexto e sétimo semestres. Na visão dos estudantes é difícil entender por que certos problemas persistem até hoje, como por exemplo, a disciplina Sensoriamento Remoto e Fotogeologia, é inconcebível ensiná-la no segundo ano do curso, ou ainda a falta de um campo na disciplina Estratigrafia. A seguir, os problemas levantados com maiores detalhes das disciplinas citadas.

\section{DISCIPLINAS CITADAS}

\section{0 - Geologia Geral - Sistema Terra}

As críticas e sugestões para melhoria desta disciplina foram divididas em dois tópicos principais: menos professores e melhor preparo dos alunos para os campos.

\section{Professores}

A disciplina possui muitos professores, o que faz com que as aulas se tornem palestras, sem uma continuidade ou ligação entre os temas de cada aula. Em uma aula um professor aborda um determinado tema e na aula seguinte outro professor fala sobre um tema completamente diferente, muitas vezes sem uma seqüência ou ligação entre estas aulas. Isso não se aplica a todas as aulas da disciplina, mas ocorre com freqüência, deixando a disciplina com alguns pedaços soltos no decorrer do ano. O ideal seria que a disciplina tivesse menos professores, um maior encadeamento lógico entre os tópicos abordados e mais dedicação, por ser a primeira disciplina geológica do curso.

\section{Aulas de Campo}

Em relação às aulas de campo, falta um melhor aproveitamento, pois o aluno chega no afloramento sem conhecimento prévio, o que poderia ser solucionado com uma boa descrição e discussão do roteiro de campo.

Uma sugestão seria que na aula anterior ao campo fosse utilizada pelo menos metade da aula para explicar com clareza quais os objetivos principais do campo e quais as características principais do local a ser visitado. Se o aluno tiver em mente de forma clara o objetivo do campo, irá direcionar melhor seu tempo. Como exemplos: se o campo é voltado para sedimentologia ou estratigrafia, comentar sobre os eventos e a sedimentação predominantes no local e como observá-las, recomendando aos alunos que revisem ou estudem um ou outro conceito útil no campo; se o campo for sobre geologia estrutural (observação de dobras) comentar sobre as possíveis causas de tais dobramentos no local, e uma revisão de utilização de bússolas.

Exemplos de alguns trabalhos de campo:

1. no primeiro campo da disciplina, sobre os granitóides de Perus, poderia ser explicado em aula, antes do campo, o que aquelas litologias representam para a região;

2. no campo sobre a Dobra de Brigadeiro Tobias, que mecanismos formaram aquela dobra, e a implicação para o estudo da Geologia no local.

Além dos tópicos acima citados, é relevante também abordar questões de atitude e segurança na aula de campo.

\section{GSA0240 - Paleontologia}

Essa é uma disciplina com sérios problemas, na forma como ela está sendo ministrada, pouquíssimos alunos são motivados a terem interesse por esta área tão importante para o geólogo.

Por se tratar de uma disciplina anual, os conteúdos ministrados em aula estão mal planejados, ou seja, precisa ser reestruturada. A grande maioria dos conceitos fica concentrada no primeiro semestre e o segundo passa a impressão de não ter a mesma quantidade de conteúdo. Poderia, portando, haver uma distribuição melhor dos assuntos ao longo do ano, para que possam ser ensinados com mais clareza.

Com relação ao conteúdo propriamente dito:

a. alguns assuntos são revisões da disciplina Geologia Geral, ou são abordados duas ou três vezes durante o curso, quando não há necessidade de tal repetição; 
b. micropaleontologia é ensinada muito superficialmente;

c. seria interessante ter uma maior integração com a disciplina Sedimentologia.

A sugestão é que o conteúdo seja apresentado de forma cronológica ao longo da disciplina, ou seja, ao longo das eras e períodos geológicos, abordando de forma conjunta fósseis, evolução da vida, tempo geológico e conceitos de estratigrafia.

Outro problema é o número muito reduzido de docentes da disciplina em relação ao que havia no passado, o que acaba estagnando e limitando os temas abordados à especialização dos docentes efetivos. A apostila utilizada no curso contém muitos erros.

Com relação aos campos, cabe a mesma sugestão com relação aos campos de Geologia Geral, uma discussão prévia dos conceitos chave, técnicas utilizadas e principais objetivos do campo, com procedimentos sistemáticos de observação, descrição e interpretação dos objetos de estudo do campo. Diversificar os locais de campo seria também interessante, além da introdução de um campo de mais de um dia de duração.

\section{0 - Geoquímica}

Uma sugestão para esta disciplina seria uma maior interação com a mineralogia, petrologias e hidrogeologia, fornecendo um maior subsídio a elas.

\section{0 - Sensoriamento Remoto}

É consenso entre os alunos que a disciplina está fora de contexto na atual posição na grade curricular de disciplinas. Uma das causas para esta situação seria a ordem da disciplina durante o curso, sendo uma disciplina anual do $2^{\circ}$ ano, faltam conceitos teóricos ao aluno para entendimento de todo o conteúdo ministrado, como, por exemplo, conceitos de geologia estrutural, matéria do $3^{\circ}$ ano, portanto posterior a Sensoriamento Remoto e Fotogeologia.

Durante o Seminário de Avaliação de Currículo foi levantado que a causa maior para o fraco aproveitamento da disciplina talvez fosse uma lacuna de conhecimento em geomorfologia, faltando, portanto uma base forte nesta área. A disciplina geomorfologia é citada em outro tópico deste mesmo texto, sobre matérias oferecidas por outros institutos.

Uma alternativa seria o desmembramento da disciplina. Ela consiste em deixar a parte de Sensoriamento Remoto no segundo ano e realocar a parte de Fotogeologia para o $3^{\circ}$ ou $4^{\circ}$ ano, junto com as disciplinas de mapeamento. Outros complementos, tais como a criação de uma disciplina introdutória de Sistema Informação Geográfica (SIG), além de uma base mais sólida em Geomorfologia, visaria melhorar a formação dos alunos, colocando-os em condições de competição com outros alunos de graduação de outras universidades.

\section{GSA0301 - Recursos Energéticos}

Essa disciplina apresenta muitos problemas. Na opinião dos alunos, ela precisa ser reestruturada completamente, pois da forma que é ensinada, não desperta nenhum interesse no aluno e tem aproveitamento muito fraco quando se trata de favorecer o aprendizado de novos conhecimentos. E isso é muito ruim, pois como pode um geólogo ser formado sem uma boa visão do quadro energético do seu país e do mundo?

As propostas para resolver esses problemas seriam:

\section{Atualização de conteúdo}

É consenso entre os alunos de que muitas informações apresentadas em aula precisam ser atualizadas, como tabelas de consumo e de tipos de energia utilizados, perspectivas de consumo, descobertas de novas fontes e tecnologias associadas a obtenção de energia. Algumas destas tabelas e informações são de décadas atrás, a área de recursos energéticos exige dados atuais de estatísticas de consumo, reservas e tecnologia utilizada, para não se correr o risco de realizar um estudo com base em dados sem valor.

\section{Formação de espírito crítico}

Uma visão crítica sobre o tema é importante nesta área de recursos energéticos, pois não basta apenas conhecer os tipos de recursos, como são obtidos, onde e como são usados, mas também suas implicações em outras áreas do conhecimento e da sociedade que não sejam associadas apenas à Geologia.

\section{GSA0307 - Estratigrafia}

Nesta disciplina os alunos sentem a necessidade de um campo mais bem estruturado, com elaboração de mapas, colunas estratigráficas etc. Um campo de estratigrafia bem elaborado é uma realidade comum em outras universidades, como a UNESP, UNICAMP, UFRGS, UNB etc.

A sugestão é de um campo mais extenso e abrangente sobre a Bacia do Paraná. Um conhecimento detalhado sobre a Bacia do Paraná é de grande importância para um geólogo da nossa região, na atual situação o aluno termina a disciplina sem esse conhecimento, o que na opinião dos alunos é grave, pois não se pode deixar de estudar uma área importante para nossa formação. Nas reuniões, os alunos expressaram fortemente suas opiniões no sentido de que é 
necessário que esta disciplina forneça base forte neste estudo.

\section{DISCIPLINAS NÃO CITADAS}

As disciplinas que não foram citadas nesse texto, na visão dos alunos estão boas, sem a necessidade de mudanças. Este é o caso de disciplinas como: Cristalografia, do $1^{\circ}$ ano; Mineralogia e Sedimentologia, do $2^{\circ}$ ano; Petrologia Ígnea e Petrologia Metamórfica, do $3^{\circ}$ ano.

\section{DISCIPLINAS OFERECIDAS POR OUTROS INSTITUTOS}

Nas disciplinas oferecidas pelos outros institutos, notase que estas necessitam de uma revisão do conteúdo, acompanhada de um maior comprometimento por parte dos docentes, que historicamente não vem ocorrendo.

As disciplinas que mais causam reclamações dos alunos são: Cálculo 1 para Geociências, Cálculo 2 para Geociências, Físico-Química, Eletromagnetismo para Geociências, Fenômenos Ondulatórios para Geociências e Geomorfologia.

A falta de compromisso dos docentes em relação as disciplinas reflete-se muitas vezes em uma postura nada profissional e de pouco caso com as aulas. Para citar apenas os últimos dois anos, houve um caso em que o docente não compareceu em praticamente $50 \%$ das aulas.

Existe uma idéia de que essas disciplinas não são importantes para a formação do geólogo, tanto por parte dos alunos como por parte dos docentes que as ministram, comprometendo muito a qualidade do curso. Um dos motivos para isto talvez esteja no próprio nome da disciplina (cálculo para Geociências, física para Geociências etc), pois não existe um cálculo específico para Geociências, esta é uma matéria de base e o interessante seria um maior contato entre o IGc e os outros institutos.

Outra falha é a alternância de docentes no decorrer dos anos não permite criar um vínculo entre o instituto, a disciplina e o docente. Sem esse vínculo, fica muito difícil ter um controle da qualidade da disciplina.

\section{CONCLUSÕES}

Serão feitas, nestas conclusões gerais sobre o curso, observações mais abrangentes e de forma mais generalizada do que foi feito na parte em que se tratava cada disciplina isoladamente.

1. Nos dois primeiros anos de curso, tanto a qualidade como a quantidade de campos realizados não desenvolvem no aluno as aptidões necessárias nos campos das discipli- nas do $3^{\circ}$ ano. Foram apontadas no texto possíveis melhorias e caminhos no sentido de preparar melhor e de forma gradual o aluno em termos de procedimentos e comportamento no campo.

2. Foi observado que no $3^{\circ}$ e $4^{\circ}$ ano ocorre uma concentração de disciplinas de alta carga horária, de campo e de sala de aula, desequilibrando a grade curricular;

3. A maioria das disciplinas necessita de pequenas mudanças, mas com caráter de síntese. A seguir serão citadas algumas disciplinas que envolvem maiores mudanças ou discussões: Sensoriamento Remoto e Fotogeologia, que será tratada com maior profundidade em outro artigo desta publicação; Recursos Energéticos, que necessita de séria reestruturação de conteúdo e metodologia de aula. Em Sistema Terra entende-se que estão sendo feitas sempre mudanças buscando melhoria e que a disciplina é de difícil tratamento, por ser a primeira disciplina geológica do curso, sendo sempre motivo de discussões sobre o programa ministrado e o grau de profundidade dos assuntos abordados, mas espera-se que sejam de alguma valia as sugestões deste texto.

Apesar dos problemas citados, a avaliação geral do curso é boa, sendo que a maioria das disciplinas que apresentam problemas, estes são pontuais, e necessitam de pequenas mudanças em alguns aspectos, e não mudanças de grande magnitude. Mas é importante ressaltar que mesmo assim é necessário que estes problemas sejam tratados seriamente e com o compromisso de que será sempre feita uma busca por melhorias.

Tão importante quanto a realização de eventos e discussões sobre a estrutura do curso é a iniciativa por parte de alunos e professores de incentivar e manter um diálogo constante sobre melhorias e mudanças, sejam elas pequenas ou de grande magnitude. Mantendo-se sempre aberta a comunicação entre os próprios alunos, e entre alunos e professores, poderemos melhorar as condições do nosso curso. Não deve ser de caráter esporádico o interesse por mudanças, a troca constante de informações e percepções é que levará a construção de um currículo consistente e conseqüentemente de profissionais melhores. 